ENSAYO

\title{
NERUDA EN EL UMBRAL DE LA CRISIS DE 1956
}

\author{
Greg Dawes \\ Universidad Estatal de Carolina del Norte
}

\begin{abstract}
Resumen: Este ensayo arguye que si bien es cierto que se produce una crisis en la vida y obra de Neruda a partir de 1956, que deja huellas nítidas en sus poemarios desde Estravagario en adelante, indicios de esta crisis pueden encontrarse en su obra incluso antes de aquel libro, concretamente en el Tercer libro de las odas (1957).

Palabras Clave: Pablo Neruda, Tercer libro de las odas, Odas elementales, crisis de 1956, socialismo real, socialismo democrático, revelaciones de Jruschov.
\end{abstract}

\section{NERUDA ON THE THRESHOLD OF THE CRISIS OF 1956}

ABSTRACT: This essay argues that while it is true that there is a crisis in Neruda's work and life in 1956 and that its traces can be seen in his books from Estravagario on, signs of the crisis can be discerned before that book, specifically in the Third Book of Odes (1957).

Keywords: Pablo Neruda; Third Book of Odes, Elemental Odes, crisis of 1956; real socialism; democratic socialism; Khrushchev's revelations.

GREg DAwES. Profesor de literatura y cultura latinoamericanas en la Universidad Estatal de Carolina del Norte. Entre otros libros, es autor de Verses Against the Darkness: Pablo Neruda's Poetry and Politics (2006), Poetas ante la modernidad. Las ideas estéticas y políticas de Vallejo, Huidobro, Neruda y Paz (2009) y Multiforme y comprometido. Neruda después de 1956 (2014). Email: gadfll@ncsu.edu. El autor agradece a Pedro Salas Camus los comentarios sobre este artículo. 


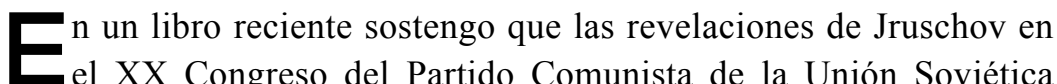
(PCUS) repercuten fuertemente en la cosmovisión de Neruda, incidiendo en su postura comunista y su estética, obligándolo a reconceptualizar ambas esferas. ${ }^{1}$ Esta crisis político-estética coincide con la otra crisis que estremece su vida personal, a saber, su ruptura con Delia del Carril y el comienzo de su vida junto a Matilde Urrutia. Todo ello hace que el bardo se desahogue en sus versos, como acostumbra a hacerlo. El esfuerzo por enfrentarse a la crisis se inicia con Estravagario (1958), desplegándose de forma velada en el silencio, la muerte, la soledad recuperada, el humor fresco y a veces negro, la ironía, la incertidumbre, la autocrítica, la crítica y el refugio en el amor de Matilde. Su empeño en asumir, absorber y tratar de superar la crisis sigue vigente en Cien sonetos de amor (1959), dedicado exclusivamente a Matilde. La dedicación sirve para coronarla, pero también para señalar a las claras que todo, incluso su compromiso político, parte, de ese momento en adelante, de su vida personal. Y no es hasta Memorial de Isla Negra (1964) que constata la crisis abiertamente y una postura clara con respecto a ella, concretamente en "El episodio", su primera crítica al estalinismo en este poemario autobiográfico. De ahí en adelante, en obras tales como Fin de mundo (1968), La espada encendida (1970), Incitación al nixonicidio y alabanza de la revolución chilena (1972), y obras postreras, la postura política empieza a registrar una condena del estalinismo, una cierta desilusión con el revisionismo soviético, un vuelco — después del enfoque en la revolución cubana (Canción de gesta, 1960) — hacia alternativas socialistas, para desembocar en el socialismo democrático de la Unidad Popular. En el ámbito estético, asevero que se manifiesta una progresión paralela: a partir de Estravagario, Neruda empieza a entregarse a la experimentación poética y a asociarse con poetas heterodoxos. Hasta aquí el resumen del argumento de mi libro. Aunque no abordo el caso, pienso - y éste es el centro de este ensayo - que los primeros rastros de dicha crisis se pueden hallar, en rigor, en el Tercer libro de las odas (1957).

${ }^{1}$ Ver Greg Dawes, Multiforme y comprometido. Neruda después de 1956 (Santiago: RIL Editores, 2014). 


\section{EN EL UMBRAL}

En un principio, el Tercer libro de las odas podría leerse como la continuidad, en la forma y el contenido, de los dos libros anteriores dedicados a la oda. También predominan en este poemario el humor, la ironía y la autocrítica como herramientas líricas que van esbozando, al decir de Jaime Concha, esa "forma singular [que] equivale a una sinécdoque del cosmos, en la medida en que participa de las fuerzas solidarias de la realidad". ${ }^{2}$ Sean epifanías de objetos orgánicos o inorgánicos, naturales o manufacturados, la "riqueza de las especies, la multiplicidad de las formas constituyen", como señala Concha, "el deleite de los ojos y de los sentidos en general". ${ }^{3}$ Así también en cuanto a la óptica política: estas odas se vinculan aún y en determinados momentos con la inexorable marcha colectiva de la humanidad y el optimismo nerudiano en plena época de la Modernidad. ${ }^{4}$ En ese sentido, podríamos decir que varios poemas a lo largo del libro reproducen el esquema estrofa/antiestrofa/epoda que apuntara Jaime Alazraki en el caso del primer poemario y cierran con una respuesta moral y política. ${ }^{5}$ Tal vez no sean tan enfáticos ni idealistas con respecto de sus conclusiones políticas, pero siguen el patrón de las odas anteriores.

Sin embargo, el grueso de los poemas en el Tercer libro de las odas se aparta de la obra anterior al abordar temas que rara vez se hallan en las primeras odas. Si vemos la arquitectura de este libro de sesenta y seis poemas, más de una tercera parte — según mis cálculos - elabora una temática sobre la soledad y la muerte, tres se refieren a Matilde, cuatro versan sobre la poética como tal y nueve se abocan a lo sociopolítico. El resto de las odas consiste en elogios de objetos orgánicos e inorgánicos. La misma temática desplegada en este poemario, entonces, muestra sin lugar a dudas una transición importante en cuanto a la cosmovisión de Neruda, por no decir una aproximación a, en palabras de Hernán Loyola,

2 Jaime Concha, "Introducción”, en Pablo Neruda, Odas elementales (Madrid: Ediciones Cátedra, 1999), 45.

${ }^{3}$ Ibídem.

${ }^{4}$ Sigo aquí la periodización que emplea Hernán Loyola, la que distingue entre el Neruda moderno (hasta 1956) y el Neruda posmoderno (a partir de esa fecha). Véase Loyola, "Neruda posmoderno", A Contracorriente 6, n. ${ }^{\circ} 1$ (2008): 1-14.

5 Jaime Alazraki, "Observaciones sobre la estructura de la oda elemental", Mester 4, n. 2 (1974), 97. 
la "única gran crisis". ${ }^{6}$ Es evidente que se produce un cambio notorio en su obra que difícilmente puede desvincularse del momento histórico y personal. Tantas meditaciones sobre la muerte y la soledad, lugares geográficos, criaturas dotadas de sentidos y la condición del propio hablante hacen pensar que se empieza a gestar en Neruda una crisis que, como pasa siempre en la obra del vate, se divulga indirectamente en sus versos.

No parece fortuito tampoco que este libro se publicara en 1957, un año después de las revelaciones de Jruschov en el XX Congreso del PCUS y dos años después de la ruptura con Delia. De hecho, se podría inferir que las reflexiones sobre la muerte y la soledad se deben a esa coyuntura político-personal y, por ende, nos ubican en el umbral de la crisis de 1956. Estamos algo lejos todavía del desahogo inicial de dicha crisis, que se puede apreciar en Estravagario, poemario en el cual el vate blande la ironía, el sarcasmo, la crítica, la autocrítica y el humor como armas poéticas, y se vale del lado juguetón y humorístico brindados por su amor a Matilde para defenderse ante el asedio de la conmoción desatada por la crisis. Nos hallamos más lejos aún del comienzo de la solución a la crisis política que se brinda en "El episodio", en $\mathrm{Me}$ morial de Isla Negra. No obstante, en el Tercer libro de las odas ya se aprecian los efectos iniciales de dicha crisis.

\section{EXCURSUS}

Para llegar a esta determinación, es decir, para establecer un vínculo entre el sujeto poético que se proyecta en el Tercer libro de las odas y el autor de carne y hueso en que descansa mi argumento, hay que cuestionar la teoría postestructuralista que niega o cree socavada esa relación. Si predomina en la poesía nerudiana una plasmación autobiográfica filtrada siempre por la mediación imperfecta del lenguaje, y si, como ha observado Alain Sicard, "el Yo nerudiano es insoslayable" y el sujeto poético canibaliza al "Yo biográfico", se puede argumentar a favor de la singularidad del sujeto y en contra del relativismo. ${ }^{7}$ Esa incer-

${ }^{6}$ Hernán Loyola, "Guía a esta sección de Neruda (nota al texto)", en Pablo Neruda, Antología general (Lima: Real Academia Española, 2010), LXXXV-CX.

${ }^{7}$ Véase Alain Sicard, "El yo nerudiano", en El mar y la ceniza. Nuevas aproximaciones a la poesía de Pablo Neruda (Santiago: LOM Editores, 2011), 39-50. También, Hernán Loyola, "El ciclo nerudiano 1958-1967: tres aspectos", Anales de la Universidad de Chile, año 129, $\mathrm{n}^{\circ}$ 157-160 (1971): 248. 
tidumbre epistemológica se destaca en particular en los estudios sobre el autor y la autobiografía en boga en los años setenta y ochenta. Roland Barthes, por ejemplo, considera que la escritura es un sitio "neutro" en que el sujeto se desliza y la identidad se pierde. Una vez narrado un acontecimiento, sostiene el crítico francés, se vuelve "intransitivo", vale decir, imposible de vincular con la biografía del autor, ya que no habría ningún puente entre el autor y su texto. ${ }^{8} \mathrm{~A}$ fin de cuentas es "el lenguaje que habla, no el autor", afirma Barthes en su célebre ensayo "La muerte del autor". ${ }^{9}$ Allí cierra sus palabras con esa reconocida frase tan en el aire en los años 60: el que ocupa el lugar de la multiplicidad "es el lector, y no, como se ha dicho hasta ahora, el autor". ${ }^{10}$ Se entiende que Barthes trata de contrarrestar la influencia en esta época (1968) del biografismo, y ello explica por qué lleva su argumento al extremo y toma posturas hiperbólicas; sin embargo, eso en sí no corrobora sus conclusiones. De hecho, se ve claramente que el lenguaje, primordial según Barthes, no es un campo de mediación dialéctica entre el autor implícito y el lector, sino que es efectivamente "intransitivo". Como tal, se le confiere al autor únicamente un rol como "una instancia de la escritura". ${ }^{11}$ Si eso no deja de ser cierto en parte, subestima, también, el rol del autor. Si siguiéramos esta teoría al pie de la letra, todos los autores - Barthes incluido - tendrían la misma función, y no se apreciarían el talento y originalidad de determinados escritores, como el mismo Neruda.

Aunque Foucault se refiere a la función del autor en el discurso y pareciera reconocer la presencia y el peso del escritor como tal (la persona de carne y hueso) sin sugerir una equivalencia entre los dos, reitera a su vez la postura hiperbólica de Barthes sobre la muerte o la au-

${ }^{8}$ Roland Barthes, "The Death of the Author", en Image-Music-Text (Nueva York: Hill and Wang, 1978), 142. Según Barthes, el autor crea un texto pero, en el momento de crearlo, viene a formar parte del lenguaje — socializado- y deja de pertenecer al autor. Obras como, por ejemplo, Rayuela, de Julio Cortázar, o La nueva novela, de Juan Luis Martínez, le ceden el paso a la creatividad del lector, de tal suerte que en estos trabajos éste llega a tener un rol, en la práctica, más significativo que el del autor. Los textos que se prestan a dicha recreación por parte del lector son "escribibles", a diferencia de las obras decimonónicas — las "legibles"— en que se deja poco espacio para la participación del lector.

\footnotetext{
9 Ibídem, 143.

${ }^{10}$ Ibídem, 148.

${ }^{11}$ Ibídem, 145.
} 
sencia del autor, y así pierde de vista el agenciamiento del escritor. ${ }^{12} \mathrm{Se}$ trata, entonces, de reanudar el lazo con el escritor sin caer en la falacia biográfica. En el caso concreto de Neruda, si bien es cierto, como lo ha señalado María Luisa Fischer, que el poeta inventó "personas poéticas" en su obra, lo hizo, como afirma ella, a base de lo biográfico. ${ }^{13}$ Ello no quiere decir, naturalmente, que esos personajes sean un reflejo exacto de Neruda, pero sí que establecen una correspondencia con la persona de carne y hueso. Incluso puede haber una conexión más estrecha entre las "máscaras" que se inventa el poeta y su vida cotidiana. ${ }^{14} \mathrm{Y}$ eso es lo que sostiene Sicard cuando asevera que "el Yo nerudiano es insoslayable". Es a base de este razonamiento que presento a continuación una interpretación sobre las huellas de la crisis política y vital de Neruda en el Tercer libro de las odas.

\section{HACIA UNA INDIVIDUALIDAD RECUPERADA}

Si el terremoto político que estremeció la vida de Neruda en 1956 se junta con el personal (la ruptura con Delia), es paradójicamente la reconquista de la individualidad lo que va a permitir que Neruda supere la crisis. Si, como sostienen Robert Pring-Mill y Sicard, en las Odas elementales el sujeto poético busca de manera "irrealizable" volverse transparente — sin mediación al aparecer - y, de ese modo, captar las maravillas sociales y naturales que lo rodean, en el Tercer libro de las odas ya inicia la recuperación de la soledad e individualidad abandonadas prácticamente después de la etapa residenciaria. ${ }^{15}$ De este libro en adelante, entonces, comienza a renombrar la soledad como parte imprescindible en su vida.

12 Michel Foucault, "What is an Author?", en Language, Counter-Memory, Practice, ed. Donald F. Bouchard (Ithaca, NY: Cornell University Press, 1977).

${ }^{13}$ María Luisa Fischer, Neruda: construcción y legados de una figura cultural (Santiago: Editorial Universitaria, 2008).

${ }^{14}$ Ver Octavio Paz, "Máscaras mexicanas", en El laberinto de la soledad, $2^{\mathrm{a}}$ ed. (México: Fondo de Cultura Económica, 1998): 10-17. En este caso, se trataría del vínculo — estrecho o suelto- entre el escritor y la persona (el "yo") que aparece en sus obras.

${ }^{15}$ Robert Pring-Mill, "El Neruda de las Odas elementales", en Coloquio Internacional sobre Pablo Neruda (la obra posterior a Canto General), ed. Alain Sicard (Poitiers: Centre de Recherches Latino-Américaines, 1979), 279. 
Esta restauración del yo como individuo independiente de su quehacer político se elabora, por ejemplo, en "Oda al mes de agosto", donde, empleando un apóstrofe, vuelve a conectarse con el invierno:

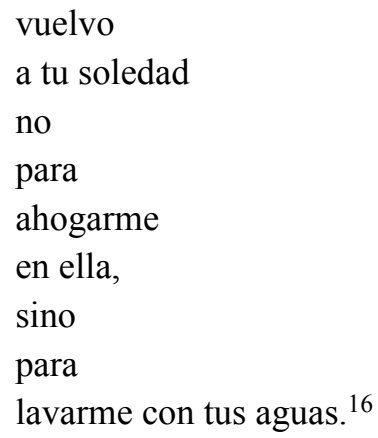

Se aclara, entonces, que no se trata de perderse en la soledad, en la alienación, sino de volver a tomar contacto con su individualidad. Es más: pareciera indicar que este aislamiento puede darle la oportunidad de sobreponerse a algo no nombrado. Y hay que tomar esta postura en cuenta a la hora ponderar las observaciones que siguen a continuación, hacia el final del poema:

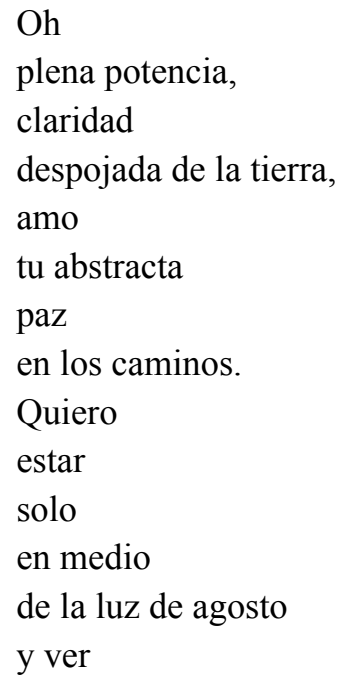

${ }_{16}$ Pablo Neruda, Nuevas odas elementales / Tercer libro de las odas, ed. Hernán Loyola (Buenos Aires: Debolsillo, 2003), 205. 
así

sin sangre

por una vez

la vida:

verla

como una

nave

deshabitada

y bella,

sin más aroma que el aire marino

o el invisible de un romero amargo.

Paso a paso,

sin nada:

no hay sino

luna y nieve.

Y ando hasta sin mí

por fin,

en la más clara

claridad de la tierra. ${ }^{17}$

Nuestro impulso inicial es asociar a este sujeto con el "hombre invisible" de las Odas elementales, cuyo propósito es justamente el de grabar en su obra el trabajo humano y la labor de la naturaleza, registrando así la teoría del valor, la explotación y la alienación, y apuntando hacia su abolición en una sociedad más justa. Pero, ¿cómo cotejar esta parte del poema con la anterior? Lo que queda claro de entrada es que la soledad se concibe como algo positivo, que permite que el hablante guarde la ilusión de percibir la vida como una "nave deshabitada / y bella". Por ende, no estamos ante la alienación perniciosa y objetiva que el sujeto residenciario percibe en la naturaleza y la sociedad moderna. Tampoco nos encontramos en el terreno del hablante de las Odas elementales, que proclamaba: "yo quiero / que todos vivan / en mi vida / y canten en mi canto, / yo no tengo importancia, / no tengo tiempo / para mis asuntos". ${ }^{18}$ Más bien se trata de aislarse para volver a retomar el contacto con la naturaleza y sintonizarse con ella.

${ }^{17}$ Neruda, Nuevas odas, 206-207.

${ }^{18}$ Pablo Neruda, Odas elementales [1954], 6 a ed. (Barcelona: Bruguera, 1986). 
De manera parecida, "Oda al camino", que se hace eco sin duda del reconocido poema "Caminante no hay camino", de Antonio Machado, articula otra conceptualización de la individualidad. A diferencia del hombre invisible que se desborda y se vuelca hacia el compromiso político a expensas del yo, éste desea

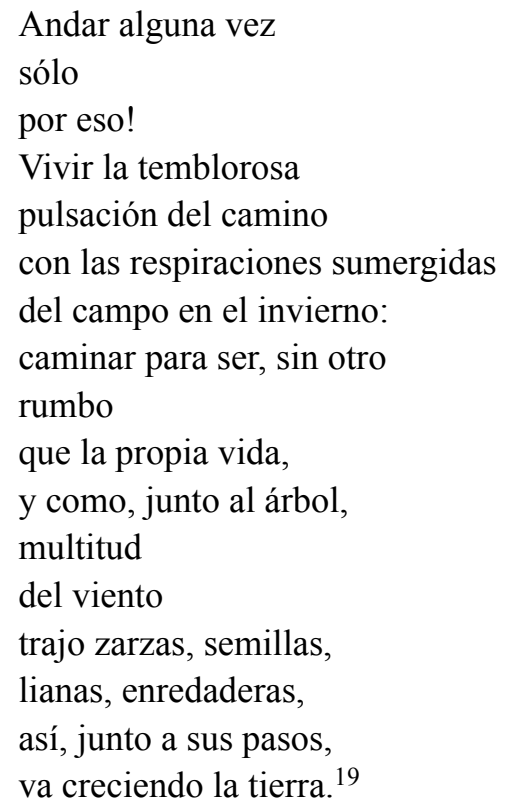

¿Abandonarse entonces al aislamiento, a la alienación? No, porque, como lo indica el hablante con anterioridad, las "soledades cierran / sus ojos / y sus bocas / sólo / al transitorio, al fugaz, al dormido. Yo voy despierto". ${ }^{20}$ Despierto, consciente de que está eligiendo la soledad - percibida como regeneradora - como para volver a gozar la vida, pero sin entregarse en ningún momento al individualismo y a la enajenación. El redescubrimiento de la naturaleza y su ligazón "orgánica" - diría el joven Marx - hace que vuelva a examinarse:
Ah viajero, no es niebla, ni silencio,

\footnotetext{
${ }^{19}$ Neruda, Nuevas odas, 253.

${ }^{20}$ Ibídem, 252.
} 
ni muerte,

lo que viaja contigo,

sino

tú mismo con tus muchas vidas.

Así es como, a caballo,

cruzando

colinas y praderas,

en invierno,

una vez más me equivoqué:

creía

caminar por los caminos:

no era verdad,

porque

a través de mi alma

fui viajero

y regresé

cuando no tuve

ya secretos

para la tierra

$\mathrm{y}$

ella

los repetía con su idioma. ${ }^{21}$

Momento de reflexión y de búsqueda, el problema que lo aqueja es psicológico: se trata de un viaje hacia adentro, de retrotraerse y buscar su voz poética y su razón de ser de nuevo. En ésta y otras odas en que asoma la soledad, se retrata como un autoexilio deseado que le brinda la posibilidad de rehabilitarse. No obstante, los últimos versos del poema bien pueden apuntar hacia la muerte como punto de enfoque o de fijación: "De una manera o de otra / hablamos o callamos / con la tierra". ${ }^{22}$ Por un lado, cabe la posibilidad de interpretar estos versos como expresión metafórica de la vida o la muerte, y de igual modo nuestro destino final que es el fallecimiento. Por otro lado, tal vez se esté refiriendo al

${ }^{21}$ Neruda, Nuevas odas, 254.

22 Ibídem. 
silencio que se guarda en determinados momentos en contacto con la tierra. El caso es que la soledad tal y como se concibe en este poemario linda con la muerte.

\section{LA PRESENCIA DE LA MUERTE}

Esta tendencia traba un vínculo con las odas en que el sujeto presencia o se imagina la muerte en otros seres. Es el caso de la "Oda a un gran atún en el mercado". "En el mercado verde", reza la primera estrofa, "bala / del profundo / océano, / proyectil / natatorio, / te vi, / muerto". El atún despierta en el poeta la imagen de un ser, un "proyectil natatorio", que viene "de lo desconocido, / de la / insondable / sombra, / agua / profunda" y sólo ese atún, paradójicamente, sobrevivía. Hemos de entender que sobrevive "alquitranado, barnizado" y como "testigo / de la profunda noche". ${ }^{23}$ Antítesis que se profundiza cuando se comenta que esta "bala oscura / del abismo" siempre está "renaciendo", "circulando en la velocidad", y explorando la muerte. Aunque es un "despojo muerto", al decir del vate, pareciera recobrar la vida, pareciera encarnar la vida que fue:

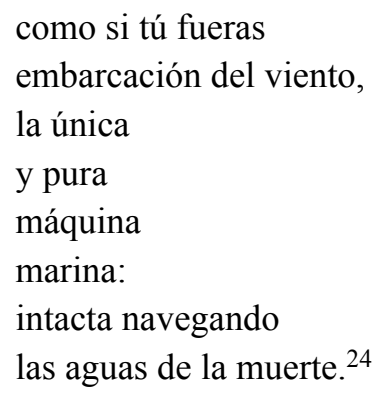

Se cierra así la asociación entre el océano y el fallecimiento y, con este remate, la oda se vuelve una meditación sobre la muerte. Viajero que rozaba la muerte a diario, que era parte vital de su existencia, el atún se vuelve "despojo muerto" que, sin embargo, al estar íntegro emana la vida que lo impulsaba.

\footnotetext{
${ }^{23}$ Ibídem, 225.

${ }^{24}$ Ibídem, 227.
} 
Parecida es la "Oda a un albatros viajero", al ser una consideración sobre la vida y muerte de esa ave. El punto de partida es la imagen de un gran albatros que

cayó
en las húmedas
arenas.
En este
mes
opaco, en
este día
de otoño plateado
y lloviznero,
parecido
a una red
con peces fríos
y agua
de mar.
Aquí
cayó
muriendo
el ave magna.

De ahí pasa a una serie de preguntas: "Por qué? Por qué? Qué sal, qué ola, qué viento / buscó en el mar? / Qué levantó su fuerza / contra todo / el espacio? / Por qué su poderío en las más duras / soledades?"26 Siguen a continuación conjeturas con respecto del viaje del albatros. En ese sentido, llaman la atención estos versos: "y el albatros errante / en la interplanetaria / parábola / del victorioso vuelo / no encontró sino días, / noches, agua, / soledades, /espacio". ${ }^{27}$ Pareciera ser, entonces, un viaje infructuoso - rematado con el asíndeton - que pese a la majestad y al empeño de esta ave termina con el enfrentamiento con la soledad y la muerte. A los ojos del hablante, su viaje solitario y sin embargo digno

\footnotetext{
${ }^{25}$ Neruda, Nuevas odas, 208-209.

${ }^{26}$ Ibídem, 209.

${ }^{27}$ Ibídem, 210.
} 
no se conmemora sino que pareciera pasar al anonimato. De ahí que no vayan a erigirle una estatua a este "héroe" pero sí a aquellos que participaron en la guerra y mataron a ciudadanos inocentes, que destruyeron colegios, que expropiaron "las tierras de los indios", y aquellos que, a nivel simbólico, cazaron palomas y exterminaron "cisnes negros". ${ }^{28}$ Por eso mismo, Neruda busca rescatar a este "rey del viento" para elogiarlo y conmemorarlo en su oda. Pero también va más allá de la observación y meditación sobre el albatros que encuentra muerto; se trata de un retrato que deja entrever las costuras entre la vida de este animal y la de los seres humanos. Antropomorfiza a esta ave al tomar en cuenta el hallazgo de las soledades tanto en la geografía chilena como en su propia conciencia, al considerar, en otro momento del poema, que el albatros alberga una antitética "profecía muda", así como al proyectarlo como héroe. ${ }^{29}$ Los versos que cierran el poema, sin embargo, elaboran una similitud con el sujeto poético, vale decir, con la autoimagen que se crea el poeta: "Oh capitán oscuro, / derrotado en mi patria, / ojalá que tus alas / orgullosas / sigan volando sobre / la ola final, la ola de la muerte". ${ }^{30}$ Por una parte, la referencia al "capitán" - muy clara para todo lector de la obra de Neruda - es una autodenominación del yo que se proyecta en varias obras del poeta. Imposible no pensar en la figura del capitán y del héroe en sus poemarios, en lo que Hernán Loyola estima que es su etapa moderna. Por otra parte, si el poema mismo establece lazos entre esta ave y Neruda, también destaca las dudas que empiezan a incidir en su autoimagen a partir de la crisis de 1956: las preguntas que plantea, el retrato de un héroe "derrotado" que "ojalá" pueda seguir "volando sobre / la ola final, la ola de la muerte". La insistente presencia de la muerte en sí diverge de aquella etapa en su obra que va de la Tercera residencia al primer libro de las odas.

\section{EL YO Y LA MUERTE}

La fragilidad y vulnerabilidad del sujeto poético se hacen patente en particular en los poemas que abordan el tema de la muerte desde el punto de vista del yo. Ese es el caso, por ejemplo, de "Oda a un camión

\footnotetext{
${ }^{28}$ Ibídem, 212.

${ }^{29}$ Ibídem, 211.

${ }^{30}$ Ibídem, 213.
} 
colorado cargado con toneles". Con versos que recuerdan al poema "El pájaro" de Octavio Paz, comienza con la representación de lo que parece ser una naturaleza muerta. El sujeto se halla en medio de la naturaleza y, a juzgar por la personificación, en armonía con ella:

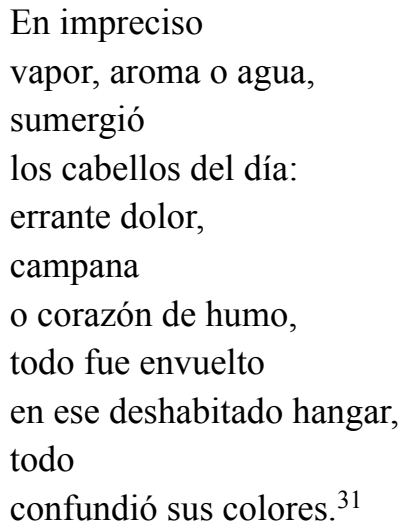

Especie de conversación en que quien cuenta la historia le advierte a su interlocutor que "espere" y que "no se asuste", y al reiterar esas frases nos va preparando para un cambio radical, que se marca a continuación: "Entonces / como un toro / atravesó el otoño / un camión colorado / cargado con toneles". 32 "Instantánea, iracundo", agrega unos versos más abajo, "preciso y turbulento, / trepidante y ardiente / pasó / como una estrella colorado". Y este acontecimiento, claro, altera al hablante y su percepción de la naturaleza y su vida: "todo cambió: / los árboles, la inmóvil / soledad, el cielo / y sus metales moribundos / volvieron a existir". ${ }^{33}$ Curiosa yuxtaposición dialéctica: lo que vuelve a existir es la "inmóvil soledad" y los "metales moribundos" junto con "los árboles" y "el cielo", es decir, la coexistencia entre la vida y la muerte. El acontecimiento fue, nos cuenta a continuación, "como si desde el frío de la muerte / un meteoro / surgiera y me golpeara / mostrándome / en su esplendor colérico / la vida". ${ }^{34}$ Compenetración dialéctica de los términos "esplendor" y "colérico", en esta oda el hablante

\footnotetext{
${ }^{31}$ Neruda, Nuevas odas, 254.

${ }^{32}$ Ibídem, 255.

${ }^{33}$ Ibídem, 256.

${ }^{34}$ Ibídem, 257.
} 
se enfrenta con la vida y la muerte en un instante, y se aferra a la vida en una rearticulación del clásico tema del carpe diem. Pero vale la pena subrayar el hecho de que el sujeto estaba en sintonía con esa naturaleza que ofrecía su inmovilidad y sus metales moribundos hasta que el acto del camión lo despertó y "acumuló / en mi pecho / desbordante / alegría / y energía". ${ }^{35}$

En "Oda al tiempo venidero" se recalca el enfrentamiento con la muerte y se establece un contraste abrupto con la maravillosa "Oda al tiempo" del primer libro. Si en aquel poema se celebraba cómo el tiempo fluía en el hablante y su amada, en éste el tiempo pesa, se va acumulando en él, encaminándolo hacia la muerte, y presentándolo con más incertidumbres que certezas. De esa manera lo describe en la estrofa primera:

Tiempo, me llamas. Antes

eras

espacio puro,

ancha pradera.

Hoy

hilo o gota

eres,

luz delgada

que corre como liebre hacia las zarzas

de la cóncava noche. ${ }^{36}$

Si en "Oda al tiempo" el tiempo se percibía como un río que corría dentro de la pareja y la unía pese a que, simultáneamente, se describía en la tercera persona y, por lo tanto, como una fuerza externa, en este caso, en cambio, el tiempo personificado y apostrófico acecha al hablante y a nadie más. Si antes era la encarnación del amor y de esa "victoria de un solo ser final bajo la tierra", ${ }^{37}$ ahora establece su dominio por sobre el sujeto al delimitar enormemente el tiempo disponible. Del tiempo concebido como "espacio puro" pasamos al "hilo o gota". Ahora el tiempo le dice: "tus pasos apresura, / tu corazón reposa, /

\footnotetext{
${ }^{35}$ Ibídem.

${ }^{36}$ Ibídem, 371.

${ }^{37}$ Neruda, Odas elementales, 243.
} 
desarrolla tu canto". ${ }^{38} \mathrm{Y}$ esto siembra dudas en el sujeto poético: "El mismo soy. No soy? Quién, en el cauce / de las aguas que corren / identifica el río?". ${ }^{39}$ Referencia indudable a Heráclito, se van borrando las orillas entre la juventud y la mediana edad, encauzando el tiempo por una sola y fina vía. De ahí el yo enfatiza la continuidad en su vida a pesar del paso del tiempo, y dos estrofas más abajo presenta una suerte de desafío al tiempo: "Así, pues, tiempo, en vano / me has medido, / en vano transcurriste / adelantando / caminos al errante". ${ }^{40}$ Sin embargo, reconoce que el equilibrio favorece al tiempo no obstante su convicción de que es y siempre ha sido el mismo: "como animal que corre / perdiéndose en la sombra / me dices, / al oído, / lo que no me enseñaste / supe siempre". ${ }^{41}$ Versos que nos recuerdan los de "Oda al tiempo": "El tiempo es decidido, / no suena su campana, / se acrecienta, camina, / por dentro de nosotros". ${ }^{4}$

\section{LA PERSISTENCIA DE LA VOZ DE LAS ODAS ELEMENTALES}

En éste y otros muchos poemas del Tercer libro de las odas el tema de la soledad y la muerte se impone, deja su huella imborrable en el poemario. Como decía al inicio, más de una tercera parte de las odas remite a asuntos algo sorpresivos si se cotejan con el primer libro de las odas. Sin embargo, para establecer convincentemente que este libro marca el inicio de la transición provocada por la crisis de 1956 habría que tomar en cuenta los poemas que se asemejan al común de las Odas elementales. En "Oda a la ciruela", por ejemplo, poema largo que se empareja con los poemas posteriores dedicados a recuperar memorias de su infancia reunidos en Memorial de Isla Negra, celebra esta fruta pero en el contexto determinado de su infancia:

Hacia la cordillera

los caminos

viejos

iban cercados

\footnotetext{
${ }^{38}$ Neruda, Nuevas odas, 371.

${ }^{39}$ Ibídem.

${ }^{40}$ Ibídem, 372.

${ }^{41}$ Ibídem.

${ }^{42}$ Neruda, Odas elementales, 242.
} 
por ciruelos,

y a través

de la pompa

del follaje,

la verde, la morada

población de las frutas

traslucía

sus ágatas ovales,

sus crecientes pezones

en el suelo

las charcas

reflejaban

la intensidad

del duro

firmamento:

el aire

era una

flor

total y abierta. ${ }^{43}$

Desde el comienzo del poema, en que no se aprecia aún la presencia del hablante, la ciruela - personificada - se ubica en su ecosistema natural pero lo acapara al envolverlo en su aroma. Inmaduras o maduras, se comparan con "ágatas ovales" y con "crecientes pezones". Acto seguido, se introduce al sujeto poético:

Yo, pequeño

poeta

con los primeros

ojos

de la vida,

iba sobre

el caballo

balanceado

bajo la arboladura

de ciruelos. ${ }^{44}$

${ }^{43}$ Neruda, Nuevas odas, 268-269.

${ }^{44}$ Ibídem, 269. 
Este contacto es el que le permite otorgarle más peso aún a la ciruela. "Pude aspirar", agrega a continuación, "en un ramo, / en una rama, / el aroma del mundo, / su clave cristalino". ${ }^{45}$ De esa manera la ciruela opera como sinécdoque de la experiencia inhalada y hallada. Desde entonces, nos dice el hablante, todo dejó en su memoria "olor / y transparencia / de ciruela: / la vida ovaló en una copa / su claridad, su sombra, su frescura". ${ }^{46} \mathrm{El}$ ambiente y la experiencia sensorial del sujeto se ven inundados de la hipnótica ciruela. Así las cosas, la visión que ofrece el bardo es parecida a la de Odas elementales: se trata de una celebración de este elemento natural, que lo deja al sujeto ebrio de su presencia, aspecto que se aprecia en estos versos:

Oh beso

de la boca

en la ciruela,

dientes

y labios

llenos

del ámbar oloroso,

de la líquida

luz de la ciruela! ${ }^{47}$

Esto lo remite al pasado nuevamente para volver a trazar su encuentro con los ciruelos, pero también para reflexionar sobre el paso del tiempo, porque ya no es "aquel niño" que se empapó del aroma y del gusto de las ciruelas. Sin embargo, esta fruta tiene el poder de transportarlo a su infancia:

Pero, otra vez,

otra vez

vuelvo

a ser

aquel niño silvestre

\footnotetext{
${ }^{45}$ Neruda, Nuevas odas, 269.

${ }^{46}$ Ibídem, 170.

${ }^{47}$ Ibidem.
} 
cuando

en la mano levanto

una ciruela. ${ }^{48}$

Y eso lo lleva a levantar la ciruela como una "pequeña copa" - imagen recurrente en la obra de Neruda - para beber y brindar la vida con el otro, con el lector. "No sé quién eres", cierra el poema, "pero / dejo en tu corazón / una ciruela". ${ }^{49}$ En suma, no es difícil ver el parecido entre esta oda y, digamos, "Oda a la cebolla", "Oda al tomate" o, bien, "Oda al vino". 50

En "Oda a la naranja", del tercer libro, hay una variación que se produce respecto de las odas. Si los poemas en Odas elementales arrancan con la fruta o verdura para entonces establecer vínculos entre el elemento orgánico y las relaciones sociales que se posibilitan gracias a la fruta $\mathrm{o}$ verdura, en esta oda elogiar la naranja es alabar el mundo por la analogía que emplea. La comparación se establece desde el comienzo del poema:

A semejanza tuya, a tu imagen, naranja, se hizo el mundo: redondo el sol, rodeado por cáscaras de fuego:

la noche consteló con azahares

su rumbo y su navío.

Así fue y así fuimos, oh tierra, descubriéndote, planeta anaranjado.

Somos los rayos de una sola rueda

divididos

como lingotes de oro

y alcanzando con trenes y ríos

la insólita unidad de la naranja. ${ }^{51}$

\footnotetext{
${ }^{48}$ Ibídem, 171.

${ }^{49}$ Ibídem, 172.

${ }^{50}$ Ver las Odas elementales.

${ }^{51}$ Neruda, Nuevas odas, 333-334.
} 
El planeta se va asociando con el sol que a su vez se vincula con la naranja apostrófica. El sol, por su parte, está rodeado de "cáscaras de fuego" y los seres humanos son "rayos" de "una sola rueda". La naranja copia la forma esférica del sol y los matices anaranjados que emite el sol cuando se levanta o se pone, de ahí que la comparación se haga factible. Pero las flores blancas del naranjo también pueblan el cielo nocturno asemejándose a las estrellas. De ese modo, la naranja engloba el día y la noche y se mimetiza con el planeta Tierra. Esa síntesis de la naranja y el mundo se subraya en los últimos versos señalados arriba. Haciendo una referencia a la naranja partida el poeta encuentra que se parece a una rueda en que estamos "divididos" pese a la unidad que brinda la naranja, brecha que se puede remediar con "trenes" y "ríos", imagen que hace imposible distinguir el planeta de la naranja.

En la segunda estrofa, pasa a la singularidad del contexto chileno para confirmar que el planeta es una naranja, "una fruta de fuego" 52 :

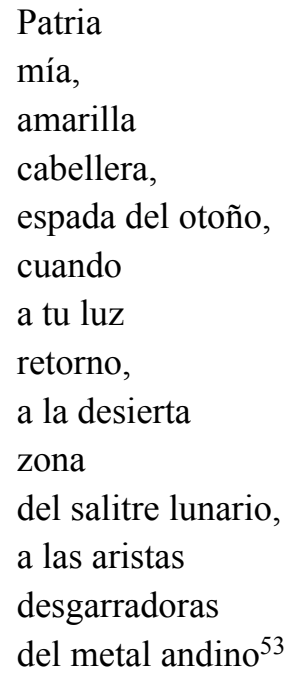

Se refiere a la región en que se siente más la presencia de los rayos del sol — el desierto de Atacama - para entonces pasar a los habitantes y el ambiente. De lo concreto pasa a lo general: el planeta, a pesar de su

\footnotetext{
52 Neruda, Nuevas odas, 335.

${ }^{53}$ Ibídem, 334.
} 
diversidad o bien por ella, es una sola unidad que se parece a la naranja, ahora personificada. Y eso se recalca en la siguiente estrofa:

En tu piel se reúnen

los países

unidos

como sectores de una sola fruta,

y Chile, a tu costado,

eléctrico,

encendido

sobre

los follajes azules

del Pacífico

es un largo recinto de naranjos. ${ }^{54}$

Lleno de naranjos y de naranjas del Valle Central que se consumen y se exportan, Chile participa de la unidad, de "una sola fruta" que es el mundo. De Chile vuelve a referirse al mundo como tal en la última estrofa:

Anaranjada sea

la luz

de cada

día,

y el corazón del hombre,

sus racimos,

ácido y dulce sea:

manantial de frescura

que tenga y que preserve

la misteriosa

sencillez

de la tierra

y la pura unidad

de una naranja. ${ }^{55}$

\footnotetext{
54 Ibídem, 335.

55 Ibídem.
} 
En una especie de eco de una oración, se alaba la luz, la dulzura, la acidez y la frescura del jugo de la naranja, señalando así su parecido geométrico al sol por un lado - el exterior- y su manera de satisfacer al ser humano, que se ha mimetizado con la naranja (el corazón del hombre es anaranjado y está lleno de esperanza). De esa manera, la naranja encierra la esencia del ser humano y el mundo, así como la insólita diversidad y particularidad geográfica y humana. No estamos lejos de "Oda a la sencillez", "Oda al tomate" u "Oda a la cebolla", poemas de Odas elementales. No hay rastro en este caso de la soledad alienante, el enfrentamiento con la muerte ni vestigios de una crisis que se aproxime. Se trata de proyectar una imagen de la totalidad del mundo en su encarnación natural y social, y de captar el optimismo, tan típico de las Odas elementales, sobre la condición humana.

Pero, volviendo al Tercer libro de las odas, tenemos que tener presente que poemas así figuran como parte mínima del poemario y el grueso de los poemas gira en torno a temas lúgubres que remiten, a mi juicio, a la crisis con la que Neruda se enfrenta en 1956. En realidad, presenciamos una lucha interna entre el poeta que valora el progreso y el optimismo asociados con el socialismo real -y el que además suprime la individualidad - , y el que busca recuperar su individualidad gracias a Matilde y su introspección, una tensión que, a la larga, lo va encaminando hacia el socialismo democrático de la Unidad Popular. La batalla mortal del poeta - ese "tiempo decidido"- que se registra en el Tercer libro de odas entonces y lo que podríamos llamar su muerte simbólica, provocadas ambas por la crisis de 1956, resultan ser momentos en la dialéctica que llevarán a este comunista por el camino de la crítica y la autocrítica hacia otro tipo de ciudad futura.

\section{BIBLIOGRAFÍA}

Alazraki, Jaime. "Observaciones sobre la estructura de la oda elemental”. Mester 4, n. ${ }^{\circ} 2$ (1974): 94-102.

Barthes, Roland. "The Death of the Author". En Image-Music-Text, 142-148. Nueva York: Hill and Wang, 1978.

Concha, Jaime. "Introducción”. En Neruda, Odas elementales, 15-56. Madrid: Ediciones Cátedra, 1999.

Dawes, Greg. Multiforme y comprometido. Neruda después de 1956. Santiago: RIL Editores, 2014. 
Fischer, María Luisa. Neruda: construcción y legados de una figura cultural. Santiago: Editorial Universitaria, 2008.

Foucault, Michel. "What is an Author?" En Language, Counter-Memory, Practice, 124-127, editado por Donald F. Bouchard. Ithaca, NY: Cornell University Press, 1977.

Loyola, Hernán. "El ciclo nerudiano 1958-1967: tres aspectos". Anales de la Universidad de Chile, año 129, n. ${ }^{\circ}$ 157-160 (1971): 235-253.

—. "Guía a esta sección de Neruda (nota al texto)". En Neruda, Antología general, LXXXV-CX.

—. "Neruda posmoderno". A Contracorriente 6, n. ${ }^{\circ} 1$ (2008): 1-14.

Neruda, Pablo. Antología general. Lima: Real Academia Española, 2010.

- Nuevas odas elementales / Tercer libro de las odas. Editado por Hernán Loyola. Prólogo de Sergio Ramírez. Buenos Aires: Debolsillo, 2003.

- Odas elementales [1954]. Sexta edición. Barcelona: Bruguera, 1986.

Paz, Octavio. El laberinto de la soledad [1950]. México: Fondo de Cultura Económica, 1998.

Pring-Mill, Robert. "El Neruda de las Odas elementales". En Coloquio Internacional sobre Pablo Neruda (la obra posterior a Canto General), editado por Alain Sicard, 261-300. Poitiers: Centre de Recherches LatinoAméricaines, 1979.

Sicard, Alain. El mar y la ceniza. Nuevas aproximaciones a la poesía de Pablo Neruda. Santiago: LOM Editores, 2011. EP 